\title{
Optimization of vibration parameters for boring bar operation by RSM and ANN
}

\author{
L.Prabhu, S.Satish Kumar, Sangeetha Krishnamoorthi, S.Prakash
}

\begin{abstract}
In boring operation, the increase in length of the boring bar tool makesan instability ofthe metal removing process; this phenomenon leads to the reduction of tool life, increase in noise and poor quality of surface finish. To overcome these criteria, a radially arranged magneto rheological fluid damper assisted tool post is used to conduct the boring operation on a conventional lathe machine. Vibration signals were monitored with the aid of piezoelectric accelerometer (vibration sensor), which is recorded in online mode \& evaluated with the use of DAQ card. MR fluid damper is modeled based on the Euler-Bernoulli's beam model. Design of experiments were conducted based on Taguchi's $\left(L_{18}\right)$ orthogonal array with the three level parameters(spindle speed, feed rate and depth of cut).The combination of optimum vibration parameters were selected with the use of response surface methodology (RSM) technique to obtain the optimum output.Performingthe machining operation with of optimum vibration parameters, reducesthe machining time and increase the productivity. Results obtained from the regression analysis shows that the regenerative chatter vibration is reduced effectively with the help of radial damper arrangement. Response surface methodology (RSM) and Artificial neural network (ANN) is applied to validate the results obtained during experimentation and to predict the behaviour of the system under any condition within the operating range. It is apparent from the analysis that the feed rate has a significant contribution for both the surface roughness and vibrational acceleration.
\end{abstract}

Keywords: Radially arranged MR fluid damper, boring bar vibration, Taguchi's orthogonal array, Response surface methodology (RSM), artificial neural network

\section{INTRODUCTION}

In the machining process, magnetorheological fluid damper could offeran excellent characteristics in vibration control. It is because of their outstanding dynamic features like robust performance, fast response, large force capacity, low power consumption and easy interference between electronic input and mechanical output. [Xiaocong Zhu et al 2012]. Surface roughness is one of the important aspect in mechanical design.Since, it affects the performance of mechanical parts

Revised Manuscript Received on September 22, 2019.

* Correspondence Author

L.Prabhu - Professor, Department of Mechanical Engineering,

Aarupadai Veedu Institute of Technology, Vinayaka Mission Research

Foundation, Deemed to be University, prabhu@avit.ac.in

Dr.S.Satish Kumar , Professor, Department of Mechanical Engineering,

Velammal Engineering College., Chennai

Sangeetha Krishnamoorthi -Associate Professor, Department of Mechanical Engineering, Aarupadai Veedu Institute of Technology, Vinayaka Mission Research Foundation, Deemed to be University sangeethas@avit.ac.in

S.Prakash -Assistant Professor, Department of Mechanical Engineering,

Aarupadai Veedu Institute of Technology, Vinayaka Mission Research

Foundation, Deemed to be University Prakash.mech94@gmail.com such as heat generation, wear, corrosion resistance, creep life and fatigue strength. In parallel, the optimal cutting conditions can minimize the cost/production time. In recent years, the optimization of cutting conditions for the purpose of vibration and minimizing the surface roughness during machining process have become an important factor for the investigation by the researchers. A.K.M. Nurul Amin et al.used an to approach for minimizing surface roughness in end milling of Mild (Low Carbon) Steel using uncoated WC-Co inserts under the influence of the magnetic field with the use of permanent magnets and performed an experimental study in different cutting conditions. The first one is cutting process under normal conditions, while the other was cut under the application of magnetic fields from two permanent magnets which is positioned on to the opposite sides of the cutter. They stated that the surface roughness is significantly reduced by as much as $67.21 \%$, while the machining is done under the influence of magnetic field. Carlos A Bavastri et al.presented a novel methodology to identify the machine tool structure and the dynamic properties by using a 1-degree-of-freedom model combined with a fractional derivative model to describe the behaviour of a viscoelastic material.Min wang et al.modeled the frictional damper and investigated its chatter suppression effect. Krishankant et al. studied an optimization of the turning process by the effects of machining parameters by applying the Taguchi methods to improve the quality of manufactured goods, and engineering development of the designs for studying the variation.

R. Kumar et al. Investigated the effect of cutting parameters (cutting speed, feed rate and approach angle) on the surface roughness in turning of $\mathrm{Al} 7075$ hard ceramic composites (10 wt. \% SiC) and $\mathrm{Al} 7075$ hybrid Composite (7 wt. \% SiC and 3 wt. \% graphite) using polycrystalline diamond tool (PCD). They used Response surface methodology (RSM) and Artificial neural networking (ANN) to validate the results obtained during the experimentation and the prediction in the behaviour of the system under any condition within the operating range. Dun Liu et al.investigated the effect of operating parameters inthe depth of penetration and surface roughness (Ra) in turning the of alumina ceramic workpieceusing abrasive water jet machine. They developed a quadratic regression model to predict the depth of penetration and $\mathrm{Ra}$ by the design of experiments using Response Surface Methodology. Ashvin J. Makadia and J.I. Nanavati studied the effect of turning parameters like feed rate, tool nose radius, cutting speed and depth of cut on the surface roughness of machining AISI 410 steel. They reported that the feed rate is the main factor, followed by tool nose radius which influence the surface 
roughness. The surface roughness were found to be increase with the increase in the feed and it decreased with an increase in the tool nose radius.

Vladimir AleksandrovichRogov and GhorbaniSiama investigated the influence of cutting parameters in the surface roughness and natural frequency in turning of an aluminum alloy AA2024. K Ramesh et al.developedthe artificial neural network (ANN) for the boring process to predict the parameters like displacement of the tool, cutting temperature and tool wear. K Venkata Rao et al.studied the effect of input cutting parameters on the tool life in boring of the steel (AISI 1040) by finding the surface roughness on the machined surface and the amplitude of workpiece vibration. K Venkata Rao et al.performed an experimental investigation performed on boring of AISI 316 steel with the cemented carbide tool inserts and studied the effect of cutting parameters like speed, feed rate and nose radius on the tool life. They used the laser Doppler Vibrometer (LDV) for online data acquisition of the work piece vibration. SundaramSaravanamurugan et al.proposedthe skyhook damper system to optimize the parameters of a damped dynamic vibration absorber to control the chatter in metal cutting systems. K. Venkata Rao et al.studied the effect of tool wear, surface roughness and the vibration of the workpiece in the boring of AISI 316 steel with carbide tool inserts. They used an ANN technique to predict the surface roughness tool wear and work piece vibration. The purpose of this study is to obtain an optimal cutting conditions to reduce the vibration and to minimize the surface roughness whileboring the AISI 1018 steel with the aid of the magneto rheological fluid damper. Spindle speed, feed rate and depth of cut were selected as cutting parameters. Table. 1 shows the cutting parameters and their levels. The experiments were performed according to the L27 orthogonal array of the Taguchi's experimental design method. The optimal cutting conditions and the significance of the cutting parameters were determined using the analysis of variance. Finally, the predicted optimal cutting conditions which were obtained by Taguchi method is verified by the confirmation tests.Experiments were carried out in an all- geared head lathe, by employing the MR fluid damper tool holder. After obtaining the experimental data, the feed-for-ward back propagation (FFBP) network is choosen for the current application to train the acquired data.

\section{Methodology}

Conventional methodology of boring bar operation results in a poor surface finish, which affects the tool life, this leads to lag in performance.So, it is important to study the boring bar tool vibration to predict the machining performance. In this paper, a radially arranged magneto-rheological damper was attached with the tool post to suppress the boring bar vibration. Twin tube magneto rheological fluid damper is used,with the piston arrangement is provided in the inner tube to adjust the fluid based on boring bar tool position. Magnetic field effect is created in the magnetorheological fluid by the magnetic (copper) coils. Electronic control circuit is used to control the magneto rheological fluid automatically. Tangentialvibration of the boring bar tool is controlled by theUp and down magneto rheological fluid dampers. Simultaneously, the axial vibration is controlled with the aid of right and left position in the magneto rheological fluid dampers.

\section{Material Selection}

The best material is the one that will serve the desired purpose at minimal cost. The following factors were considered while selecting the material for the machine tool and damping material:Ease of availability, Cost, Mechanical properties and Manufacturing considerations. Based on the above considerations Mild steel material was used as a workpiecematerial for this proposed boring bar vibration study.Work piece with a $300 \mathrm{~mm}$ length; 210mm outer diameter and $180 \mathrm{~mm}$ inner diameter.Boring operation is performed in dry machining conditions. The chemical composition of workpiece material and tool material is shown in Table 1.

Table. 1 chemical composition of work piece and tool material

\begin{tabular}{|l|l|l|}
\hline Element & $\begin{array}{l}\text { Mild steel AISI 1018 } \\
\text { (work piece) }\end{array}$ & $\begin{array}{l}\text { Boring tool } \\
\text { EN31 }\end{array}$ \\
\hline Carbon & $0.14-0.20 \%$ & $0.90-1.20 \%$ \\
\hline silicon & - & $0.10-0.35 \%$ \\
\hline Manganese & $0.60-0.90 \%$ & $0.30-0.75 \%$ \\
\hline Phosphorous & $\leq 0.040 \%$ & $0.04 \%$ \\
\hline Sulfur & $\leq 0.050 \%$ & $0.04 \%$ \\
\hline Chromium & - & $1.00-1.60 \%$ \\
\hline Iron & $98.81-99.26 \%$ & $96-97.62 \%$ \\
\hline
\end{tabular}

Table 2.Material properties

\begin{tabular}{|l|l|l|l|l|}
\hline $\begin{array}{l}\text { Material } \\
\text { property }\end{array}$ & $\begin{array}{l}\text { Density } \\
\left(\mathrm{kg} / \mathrm{m}^{3}\right)\end{array}$ & $\begin{array}{l}\text { Young's } \\
\text { modulus } \\
\left(\mathrm{N} / \mathrm{mm}^{2}\right)\end{array}$ & $\begin{array}{l}\text { Poisson's } \\
\text { ratio }\end{array}$ & $\begin{array}{l}\text { Thermal } \\
\text { conductivity } \\
(\mathrm{W} / \mathrm{m} \mathrm{K})\end{array}$ \\
\hline $\begin{array}{l}\text { Boring } \\
\text { tool, EN31 }\end{array}$ & 7.845 & $\begin{array}{l}2.15 \times \\
10^{5}\end{array}$ & 0.30 & 46.6 \\
\hline $\begin{array}{l}\text { Work } \\
\text { pieceAISI } \\
1018\end{array}$ & 7.87 & $\begin{array}{l}2.05 \times \\
10^{5}\end{array}$ & 0.290 & 51.9 \\
\hline
\end{tabular}

The boring tool geometry and the position of dampers in the boring tool holder were shown in Fig. 1 and 2, respectively. The boring tool material is chosen to be EN31, which has a high degree of hardness with compressive strength and abrasion resistance, and it is made up of high carbon alloy steel. The material properties of AISI 1018 and EN31 is presented in Table 2.

\section{EXPERIMENTAL Methods}

Conventional all geared lathe machine is used to conduct the boring operation with the aid of radially arranged magneto rheological damper tool post. This arrangementis shown in Fig 1.Spindle speed is set on a lathe machine manually for various machining condition. Radially arranged magnetorheologicalfluid damper assisted tool post is used to perform the boring operation instead of conventional tool post.Piezoelectric

Accelerometer

(vibration sensor) which is located over the boring tool bar is used to

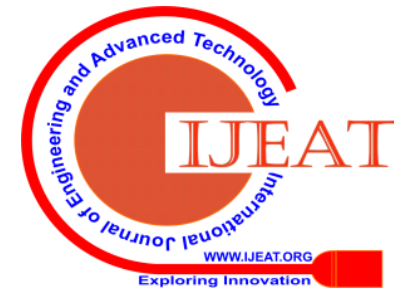


read the vibration signals during the boring operation.High speed USB carrier is used to transmit the vibration signals. Electronic circuit is attached toa microcontroller to control the viscosity of the fluid.Minitab software is used for vibration parameter validation study.DAQ system is used to measure displacement of the tool,surface roughness and tool wear in boring operations as shown in Fig.1. A radially damped boring tool holder was fabricated with the M.R damper, where the recommended spindle cutting speed, depth of cut and constant feed rate is followedin the boring operations of the mild steel cylindrical workpiece. Displacement ofthe tool (amplitude of vibration) was measured with the help of a vibration response unit. Tool wear was measured using a profilometer by calculating the tool profile dimensional difference before and after boring operations. The boring operation is influenced by various cutting parameters, such as cutting speed, depth of cut, feed rate, over hanging length, etc. As our investigation is concentrated mainly on the reduction of boring tool chatter, prominent parameters such as cutting speed, depth of cut, damping materials and position of dampers from the cutting edge are selected in various levels. The parameter levels were shown in Table 2. Experiments were carried out with various combinations of the above parameters using the full factorial method. Finally, nine data for the boring tool without a damper and 27 data for the boring tool equipped with the brass damper were measured.
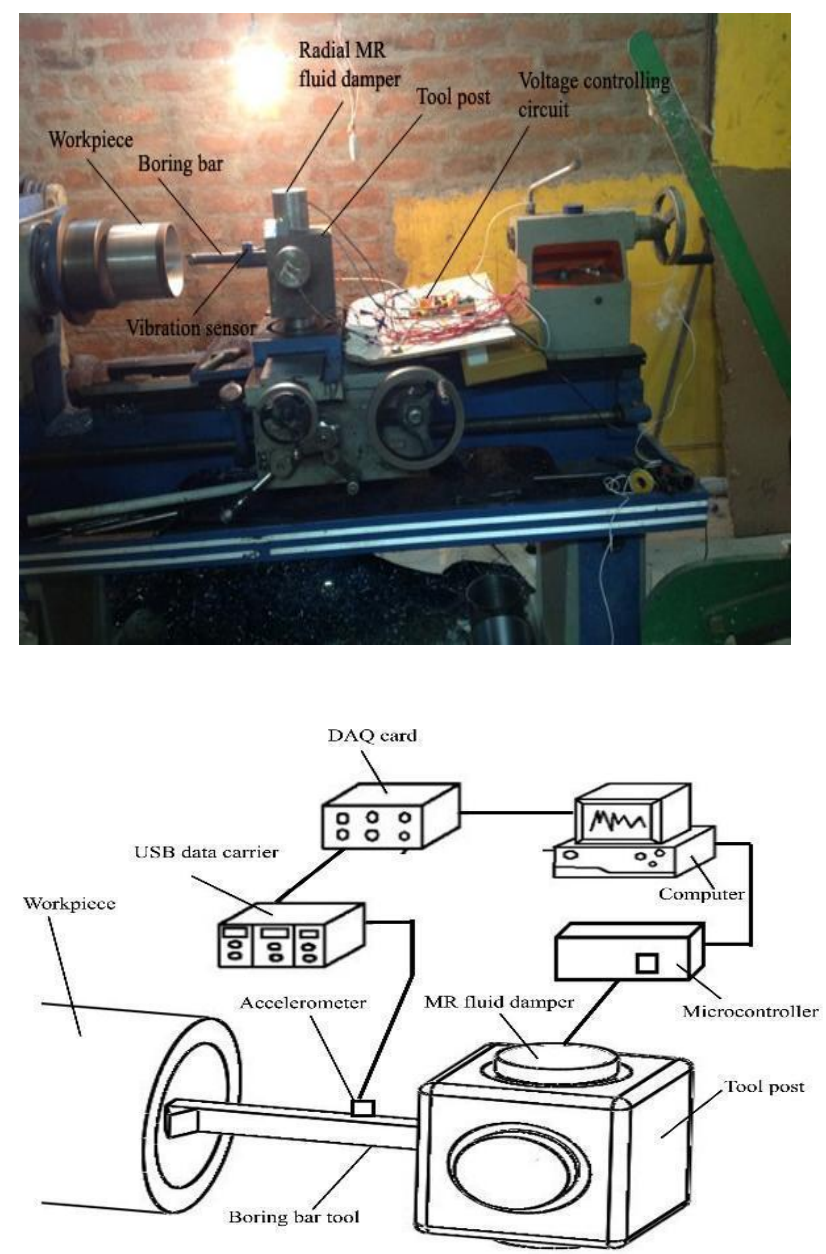

Figure 1.Experimental arrangement of a radial MR fluid damper assisted boring bar

\section{OPTIMIZATION TECHNIQUE}

Toselect anappropriate orthogonalarray of experiments, the total degrees of freedom need to be computed. The degrees of freedom were defined as the number of comparisons between process parameters that need to be made to determine which level is better and specifically how much better it is. For example, a three-level process parameter counts for the two degrees of freedom. The degrees of freedom associated with the interaction between two process parameters were given by the product of the degrees of freedom for the two process parameters. In the present study, the interaction between the cutting parameters is neglected. Therefore, there were six degrees of freedom owing to the three cutting parameters in turning operations. Once the degrees offreedom required is known, the next step will be the selection of an appropriate orthogonal array to fit the specific task. Basically, the degrees of freedom for the orthogonal array which should be greater than or at least equal to the process for those parameters. In this study, an L9 orthogonal array with the four columns and nine rows were used. This array have eight degrees of freedom and it can be handledfor three-level process parameters. Each cutting parameter is assigned to a column and nine cutting parameter combinations were available. Therefore, only nine experiments were required to study the entire parameter space using the L9 orthogonal array. The experimental layout for the three cutting parameters using the L9orthogonal array is shownin Table 2. Since the L9orthogonal array has four columns, one column of the array is left empty for the error of experiments. Orthogonality is not lost by letting one columnof the array remain empty. Table 3 shows the experimental results of tool life, cutting force, and surface roughness.Machining parameters were optimized with the use of Taguchi's $\left(\mathrm{L}_{18}\right)$ orthogonal array method,

Table 1. Machining parameters for boring operation

\begin{tabular}{|c|c|c|c|}
\hline Control variables & Level & Level & Level \\
\hline $\begin{array}{c}\text { Spindle speed } \\
(\mathrm{rpm})\end{array}$ & 1400 & 700 & 350 \\
\hline Feed rate (mm/sec) & 1 & 0.75 & 0.5 \\
\hline Depth of cut (mm) & 0.5 & 0.75 & 1 \\
\hline
\end{tabular}


Table. 2. Normalized values of the cutting parameters and cutting responses using the artificial neural network (with MR fluid damper).

\begin{tabular}{|c|c|c|c|c|c|c|}
\hline Ex. no & $\begin{array}{l}\text { Cutting } \\
\text { speed } \\
(\mathrm{rpm})\end{array}$ & $\begin{array}{l}\text { Feed } \\
(\mathrm{mm} / \mathrm{sec})\end{array}$ & $\begin{array}{l}\text { Depth of } \\
\text { cut }(\mathrm{mm})\end{array}$ & $\operatorname{RMS}\left(\mathrm{m} / \mathrm{s}^{2}\right)$ & $\begin{array}{l}\text { Surface roughness } \\
\mathrm{R}_{\mathrm{a}}(\mu \mathrm{m})\end{array}$ & $\begin{array}{l}\text { Flank wear } \\
(\mathrm{mm})\end{array}$ \\
\hline 1 & 1 & 0.5 & 0.5 & 0.95 & 0.97 & 0.46 \\
\hline 2 & 1 & 0.5 & 0.75 & 0.97 & 0.88 & 0.4 \\
\hline 3 & 1 & 0.5 & 1 & 1 & 1 & 0.6 \\
\hline 4 & 1 & 0.75 & 0.5 & 0.81 & 0.92 & 0.46 \\
\hline 5 & 1 & 0.75 & 0.75 & 0.71-- & 0.93 & 0.4 \\
\hline 6 & 1 & 0.75 & 1 & 0.92 & 0.84 & 0.6 \\
\hline 7 & 1 & 1 & 0.5 & 0.62 & 0.81 & 0.46 \\
\hline 8 & 1 & 1 & 0.75 & 0.65 & 0.92 & 0.33 \\
\hline 9 & 1 & 1 & 1 & 0.76 & 0.66 & 0.4 \\
\hline 10 & 0.5 & 0.5 & 0.5 & 0.84 & 0.69 & 0.53 \\
\hline 11 & 0.5 & 0.5 & 0.75 & 0.86 & 0.81 & 0.4 \\
\hline 12 & 0.5 & 0.5 & 1 & 0.82 & 0.91 & 0.6 \\
\hline 13 & 0.5 & 0.75 & 0.5 & 0.86 & 0.82 & 0.73 \\
\hline 14 & 0.5 & 0.75 & 0.75 & 0.85 & 0.97 & 0.8 \\
\hline 15 & 0.5 & 0.75 & 1 & 0.80 & 0.90 & 0.46 \\
\hline 16 & 0.5 & 1 & 0.5 & 0.63 & 0.80 & 0.53 \\
\hline 17 & 0.5 & 1 & 0.75 & 0.64 & 0.74 & 0.33 \\
\hline 18 & 0.5 & 1 & 1 & 0.79 & 0.66 & 0.6 \\
\hline 19 & 0.25 & 0.5 & 0.5 & 0.57 & 0.82 & 0.66 \\
\hline 20 & 0.25 & 0.5 & 0.75 & 0.751566 & 0.82 & 0.46 \\
\hline 21 & 0.25 & 0.5 & 1 & 0.670146 & 0.81 & 0.8 \\
\hline 22 & 0.25 & 0.75 & 0.5 & 0.791232 & 0.79 & 0.66 \\
\hline 23 & 0.25 & 0.75 & 0.75 & 0.85595 & 0.74 & 0.53 \\
\hline 24 & 0.25 & 0.75 & 1 & 0.830898 & 0.90 & 1 \\
\hline 25 & 0.25 & 1 & 0.5 & 0.73904 & 0.83 & 0.53 \\
\hline 26 & 0.25 & 1 & 0.75 & 0.791232 & 0.83 & 0.46 \\
\hline 27 & 0.25 & 1 & 1 & 0.032568 & 0.80 & 0.66 \\
\hline
\end{tabular}

Table. 3. Normalized values of the cutting parameters and cutting responses using theartificial neural network (withoutMR fluid damper).

\begin{tabular}{lllllll}
\hline Ex. no & $\begin{array}{l}\text { Cutting speed } \\
(\mathrm{rpm})\end{array}$ & $\begin{array}{l}\text { Feed rate } \\
(\mathrm{mm} / \mathrm{sec})\end{array}$ & $\begin{array}{l}\text { Depth of cut } \\
(\mathrm{mm})\end{array}$ & $\begin{array}{l}\text { RMS }\left(\mathrm{m} / \mathrm{s}^{2}\right) \\
\text { Surface }\end{array}$ & $\begin{array}{l}\text { Slank wear } \\
\text { roughness } \\
\mathrm{R}_{\mathrm{a}}(\mu \mathrm{mm})\end{array}$ \\
1 & 1 & 0.5 & 0.5 & 0.86 & 0.87 & 0.66 \\
2 & 1 & 0.5 & 0.75 & 0.91 & 0.95 & 0.80 \\
3 & 1 & 0.5 & 1 & 0.84 & 0.98 & 0.90 \\
4 & 1 & 0.75 & 0.5 & 0.76 & 0.88 & 0.61 \\
5 & 1 & 0.75 & 0.75 & 0.92 & 0.91 & 0.52 \\
6 & 1 & 0.75 & 1 & 0.90 & 0.84 & 0.76 \\
7 & 1 & 1 & 0.5 & 0.81 & 0.03 & 0.71 \\
8 & 1 & 1 & 0.75 & 0.79 & 1 & 0.66 \\
9 & 1 & 1 & 1 & 0.82 & 0.88 & 0.90 \\
10 & 0.5 & 0.5 & 0.5 & 0.86 & 0.91 & 0.57 \\
11 & 0.5 & 0.5 & 0.75 & 0.68 & 0.79 & 0.66 \\
12 & 0.5 & 0.5 & 1 & 0.76 & 0.83 & 0.76 \\
13 & 0.5 & 0.75 & 0.5 & 0.69 & 0.84 & 0.52 \\
14 & 0.5 & 0.75 & 0.75 & 0.46 & 0.89 & 0.71 \\
15 & 0.5 & 0.75 & 1 & 0.85 & 0.87 & 0.90 \\
16 & 0.5 & 1 & 0.5 & 0.62 & 0.78 & 0.80 \\
17 & 0.5 & 1 & 0.75 & 0.79 & 0.8 & 0.85 \\
18 & 0.5 & 1 & 1 & 0.89 & 0.03 & 1 \\
19 & 0.25 & 0.5 & 0.5 & 0.70 & 0.89 & 0.80 \\
\hline
\end{tabular}




\begin{tabular}{lllllll}
\hline 20 & 0.25 & 0.5 & 0.75 & 0.71 & 0.90 & 0.85 \\
21 & 0.25 & 0.5 & 1 & 0.77 & 0.83 & 0.76 \\
22 & 0.25 & 0.75 & 0.5 & 0.88 & 0.02 & 0.66 \\
23 & 0.25 & 0.75 & 0.75 & 1 & 0.97 & 0.95 \\
24 & 0.25 & 0.75 & 1 & 0.96 & 0.92 & 0.76 \\
25 & 0.25 & 1 & 0.5 & 0.99 & 0.02 & 0.85 \\
26 & 0.25 & 1 & 0.75 & 0.80 & 0.8 & 0.71 \\
27 & 0.25 & 1 & 1 & 0.87 & 0.84 & 0.90 \\
\hline
\end{tabular}

Table. 4. Analysis of variance for RMS (m/s2)

\begin{tabular}{|l|l|l|l|l|l|l|}
\hline Source & DF & Seq SS & Adj SS & Adj MS & F & P \\
\hline regression & 9 & 8.4959 & 8.4958 & 0.943 & 4.85 & 0.003 \\
\hline linear & 3 & 1.7474 & 1.74743 & 0.582 & 2.99 & 0.060 \\
\hline Speed (rpm) & 1 & 0.0313 & 0.0312 & 0.0312 & 0.16 & 0.694 \\
\hline Feed rate (mm/sec) & 1 & 0.3931 & 0.393 & 0.393 & 2.02 & 0.173 \\
\hline Depth of cut (mm) & 1 & 1.3230 & 1.323 & 1.323 & 6.80 & 0.018 \\
\hline square & 3 & 0.2936 & 0.293 & 0.0978 & 0.50 & 0.685 \\
\hline Speed (rpm)*Speed (rpm) & 1 & 0.0634 & 0.0633 & 0.6338 & 0.33 & 0.576 \\
\hline Feed rate (mm/sec)*Feed rate (mm/sec) & 1 & 0.1271 & 0.127 & 0.12712 & 0.65 & 0.430 \\
\hline Depth of cut (mm)*Depth of cut (mm) & 1 & 0.1031 & 0.103 & 0.10314 & 0.53 & 0.477 \\
\hline Interaction & 3 & 6.4549 & 6.454 & 2015162 & 11.05 & 0.000 \\
\hline Speed (rpm)*Feed rate (mm/sec) & 1 & 5.3067 & 5.306 & 5.30670 & 27.26 & 0.000 \\
\hline Speed (rpm)*Depth of cut (mm) & 1 & 0.2296 & 0.229 & 0.22963 & 1.18 & 0.293 \\
\hline Feed rate (mm/sec)*Depth of cut (mm) & 1 & 0.9185 & 0.918 & 0.91853 & 4.72 & 0.044 \\
\hline Residual Error & 17 & 3.3092 & 3.309 & 0.19466 & & \\
\hline Total & 26 & 11.8051 & & & & \\
\hline
\end{tabular}

Table. 5. Analysis of variance for surface roughness (um)

\begin{tabular}{|l|l|l|l|l|l|l|}
\hline Source & DF & Seq SS & Adj SS & Adj MS & F & P \\
\hline regression & 9 & 1.73763 & 1.73763 & 0.193070 & 2.34 & 0.062 \\
\hline linear & 3 & 0.64463 & 0.64463 & 0.214878 & 2.61 & 0.085 \\
\hline Speed (rpm) & 1 & 0.27627 & 0.27627 & 0.276272 & 3.35 & 0.085 \\
\hline Feed rate (mm/sec) & 1 & 0.36694 & 0.36694 & 0.366939 & 4.45 & 0.050 \\
\hline Depth of cut (mm) & 1 & 0.00142 & 0.00142 & 0.001422 & 0.02 & 0.897 \\
\hline square & 3 & 0.33563 & 0.33563 & 0.111878 & 1.36 & 0.289 \\
\hline Speed (rpm)*Speed (rpm) & 1 & 0.10578 & 0.10578 & 0.105780 & 1.28 & 0.273 \\
\hline Feed rate (mm/sec)*Feed rate (mm/sec) & 1 & 0.19560 & 0.19560 & 0.195602 & 2.37 & 0.142 \\
\hline Depth of cut (mm)*Depth of cut (mm) & 1 & 0.03425 & 0.03425 & 0.034252 & 0.42 & 0.528 \\
\hline Interaction & 3 & 0.75737 & 0.75737 & 0.252456 & 3.06 & 0.056 \\
\hline Speed (rpm)*Feed rate (mm/sec) & 1 & 0.26403 & 0.26403 & 0.264033 & 3.21 & 0.091 \\
\hline Speed (rpm)*Depth of cut (mm) & 1 & 0.10453 & 0.10453 & 0.104533 & 1.27 & 0.276 \\
\hline Feed rate (mm/sec)*Depth of cut (mm) & 1 & 0.38880 & 0.38880 & 0.388800 & 4.72 & 0.044 \\
\hline Residual Error & 17 & 1.40029 & 1.40029 & 0.082370 & & \\
\hline Total & 26 & & & & & \\
\hline
\end{tabular}

Table. 6. Analysis of variance for flank wear (mm)

\begin{tabular}{|l|l|l|l|l|l|l|}
\hline Source & DF & Seq SS & Adj SS & Adj MS & F & P \\
\hline regression & 9 & 0.009308 & 0.009308 & 0.001034 & 3.48 & 0.013 \\
\hline linear & 3 & 0.004478 & 0.004478 & 0.001493 & 5.02 & 0.011 \\
\hline Speed (rpm) & 1 & 0.003472 & 0.003472 & 0.003472 & 11.68 & 0.003 \\
\hline
\end{tabular}


Optimization of vibration parameters for boring bar operation by RSM and ANN

\begin{tabular}{|l|l|l|l|l|l|l|}
\hline Feed rate (mm/sec) & 1 & 0.000450 & 0.000450 & 0.000450 & 1.51 & 0.235 \\
\hline Depth of cut (mm) & 1 & 0.000556 & 0.000556 & 0.000556 & 1.87 & 0.189 \\
\hline square & 3 & 0.004456 & 0.004456 & 0.001485 & 5.00 & 0.012 \\
\hline Speed (rpm)*Speed (rpm) & 1 & 0.000002 & 0.000002 & 0.000002 & 0.01 & 0.938 \\
\hline $\begin{array}{c}\text { Feed rate (mm/sec)*Feed rate } \\
(\mathrm{mm} / \mathrm{sec})\end{array}$ & 1 & 0.001780 & 0.001780 & 0.001780 & 8.99 & 0.026 \\
\hline $\begin{array}{l}\text { Depth of cut (mm)*Depth of cut } \\
(\mathrm{mm})\end{array}$ & 1 & 0.002674 & 0.002674 & 0.002674 & 8.99 & 0.008 \\
\hline $\begin{array}{l}\text { Interaction } \\
\text { Speed (rpm)*Feed rate (mm/sec) }\end{array}$ & 1 & 0.000375 & 0.000375 & 0.000125 & 0.42 & 0.741 \\
\hline Speed (rpm)*Depth of cut (mm) & 1 & 0.0000300 & 0.000000 & 0.000000 & 0.00 & 1.00 \\
\hline $\begin{array}{c}\text { Feed rate (mm/sec)*Depth of cut } \\
(\mathrm{mm})\end{array}$ & 1 & 0.000075 & 0.0000300 & 0.000300 & 1.01 & 0.329 \\
\hline Residual Error & 17 & 0.005055 & 0.005055 & 0.000075 & 0.25 & 0.622 \\
\hline Total & 26 & 0.014363 & & & & \\
\hline
\end{tabular}

\section{EFFECT OF SURFACE ROUGHNESS ON BORING TOOL} VIBRATION

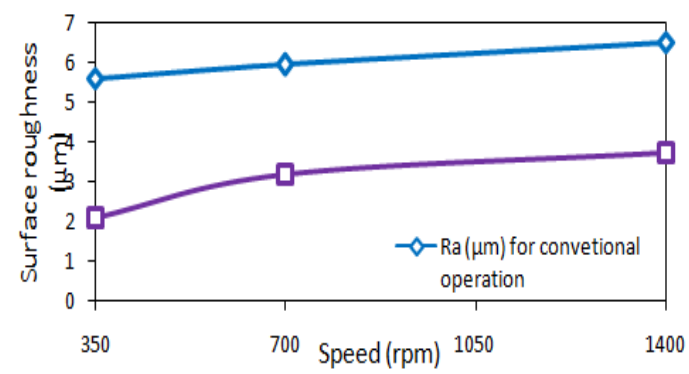
Fig. 2.effect of cutting speed on surface roughness for
conventional and MR fluid operation

The surface roughness values are higher for the workpiece machined with the tool holder without the damper due to the high-amplitude vibrations that occurred during the process. The workpiece machined with the tool holder with the MR fluid damper have relatively low surface roughness, and their values do not change significantly with the increase in the depth of cut as shown in Fig.2. Thus, the dynamiccharacteristicsof magneto rheological fluid was effective to avoid chatter and allowed for an increase in the material removal rate.

VII ARTIFICIAL NEURAL NETWORK (FFBPNN)

Researchers use the application of the artificial neural networks (ANN) model for the modelling purpose in different areas including machining very widely; however, untilnow there have been no clear rules that could serve as a basis to be followed in this study of producing the perfect model. This study considers the factors, which could be influencing the effectiveness of the ANN model developed, based on the item required by the Matlab ANN toolbox in order to develop the ANN model. A majority of ANN architectures based on feed-forward networks, which were mostly trained from the input data using error back-propagation algorithm. Each input node represents an independent variable while the output nodes give the dependent variables. Hidden layers were employed to perform nonlinear transformations on the input space and are

used for computation purpose. Three nodes in the input layer stand for the three decision values of the case study, which are cutting speed, feed rate, and approach angle. One node in the output layer stands for the predicted surface roughness value of the case study. It could be summarized inthe literature review that researchers have tried different model structures in order to get the best prediction result. It also concluded that researchers are free to test at any number of hidden layers with any number of nodes in each hidden layer. Inconsidering too many nodes result in a waste of computer memory and computation time, while too few nodes may not provide the desired data control effect. In relation to this study, the parameters of the artificial neural network process are given in Table 1. The network is trained using the implemented feed-forward backpropagation, the training was carried out by adjusting the weight connections between neurons with the aim of reducing the Mean square error (MSE) between the predicted and the experimental outputs below an acceptable threshold, thus minimizing the performance of MSE function. A successful training is achieved after 13 iteration with MSE error of 0.54382 and 6 validating checks. The $\mathrm{R}$-value for the training data is at 0.98433 and the $\mathrm{R}$-value for the testing data is 0.9766 Algorithms, progress, and R-value of ANN model are shown in Fig. 4.

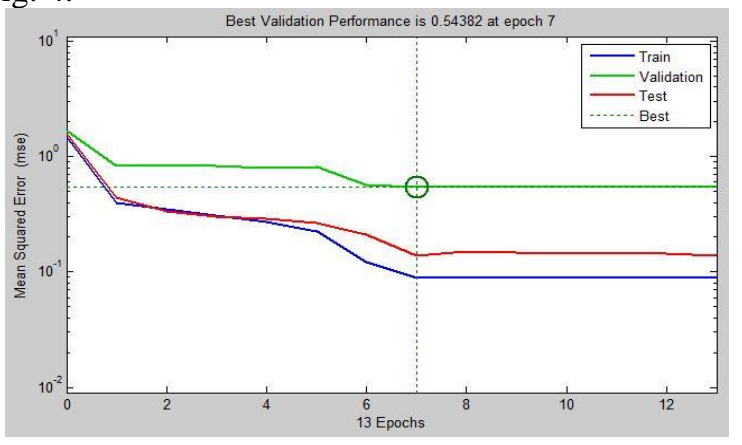

Fig.3. Iteration number vs Mean square error (mse) 


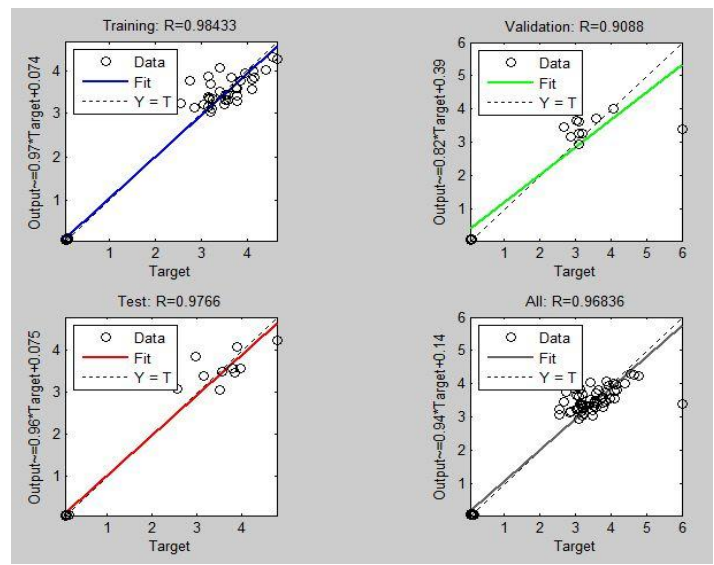

Fig.4. Result for train, test and validation of the comparison of $\mathrm{ANN}$ results with experimental measurements

\section{RESPONSE SURFACE METHODOLOGY (RSM)}

RSM have been used for the analysis of the results obtained during experimentation. RSM is a collection of experimental strategies, mathematical methods, and statistical inferences that enable an experiment to make efficient empirical exploration of the system of interest. RSM can be defined as a statistical method that uses quantitative data from appropriate experiments to determine and simultaneously solve multi-variable equations. This method is broadly used in many interdisciplinary fields to statistically analyze the results. Response surface methodology designs (RSM) were developed to study the relationship between one or more output variables and number of independent or controllable variables of the process. The output variables are investigated and predict by RSM technique.Effect on a particular response from a given set of input variables over some specified region wereanalyzed.

RMS (m/s2) vs Feed $(\mathrm{mm} / \mathrm{sec})$, Cutting speed ( $\mathrm{rpm})$

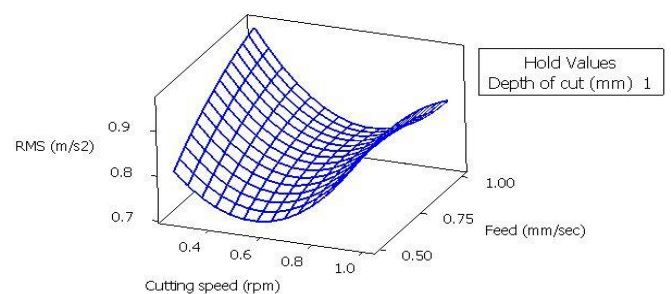

Surface roughnes vs Depth of cut ( $\mathrm{mm}$, Cutting speed (rpm)

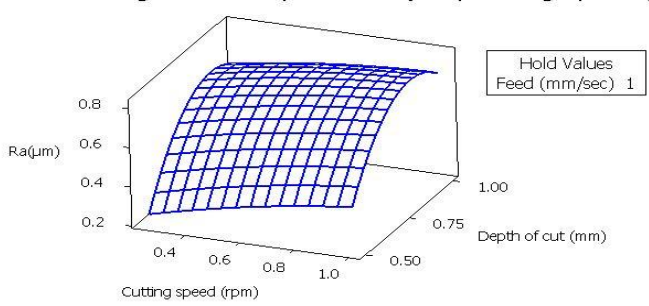

RMS (m/s2) vs Depth of cut (mm), Cutting speed (rpm)

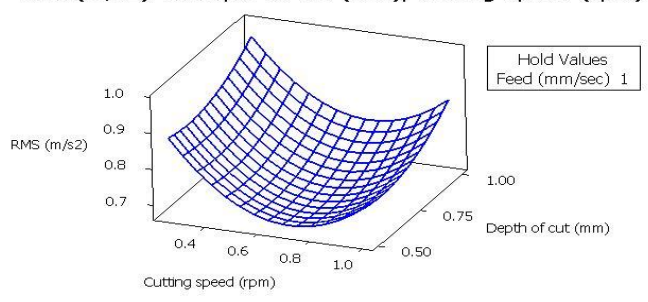

Fig.5. The various 3D plots for without MR fluid damper for different interaction ( $\mathrm{AB}, \mathrm{AC}$ and $\mathrm{BC}$ ) for vibration signal.
Surface roughnes vs Feed ( $\mathrm{mm} / \mathrm{sec}$ ), Cutting speed (rpm)

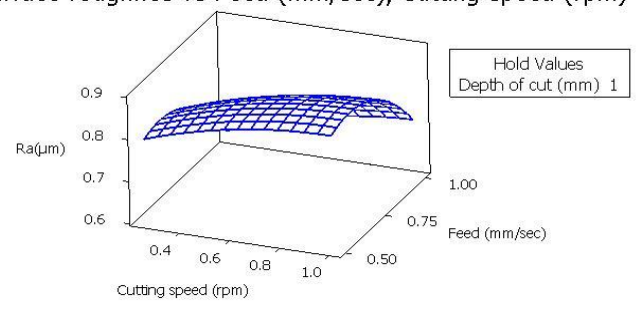

RMS (m/s2) vs Depth of cut $(\mathrm{mm})$, Feed $(\mathrm{mm} / \mathrm{sec})$

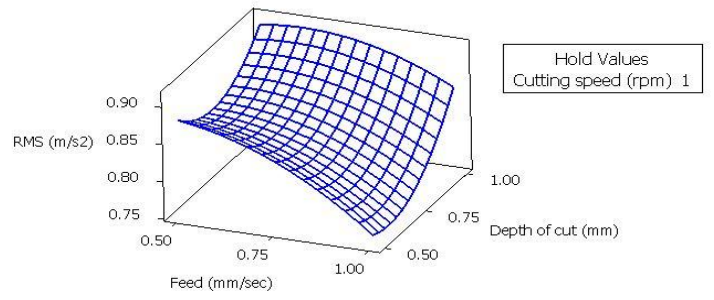

Surface roughnes vs Depth of cut $(\mathrm{mm}$, Feed $(\mathrm{mm} / \mathrm{sec})$

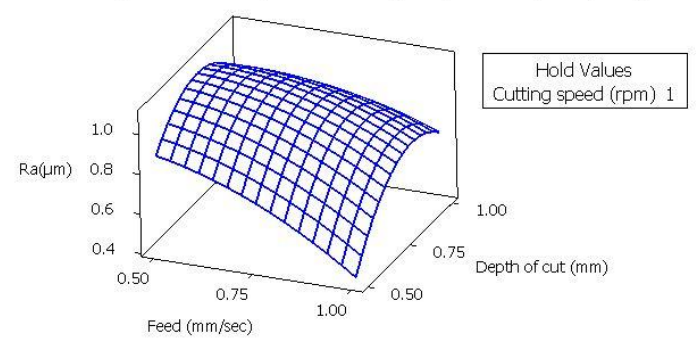

Fig.6. The various 3D plots for without MR fluid damper for different interaction ( $\mathrm{AB}, \mathrm{AC}$ and $\mathrm{BC}$ ) for surface roughness.

Flank wear $(\mathrm{mm})$ vs Feed $(\mathrm{mm} / \mathrm{sec})$, Cutting speed (rpm)

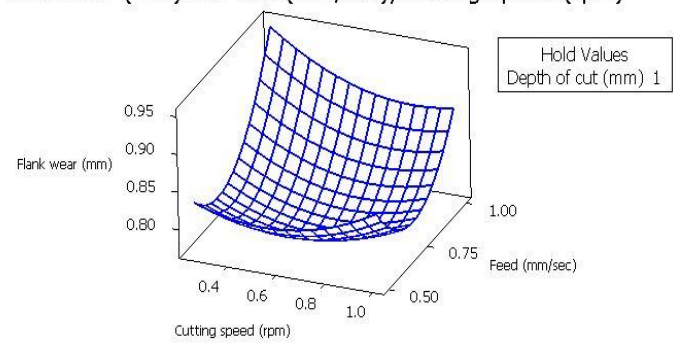

Flank wear $(\mathrm{mm})$ vs Depth of cut $(\mathrm{mm})$, Feed $(\mathrm{mm} / \mathrm{sec})$

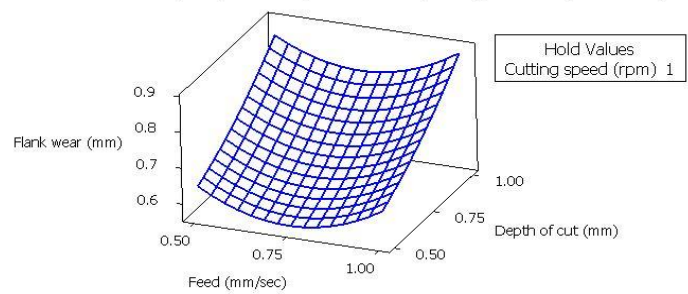

Flank wear (mm) vs Depth of cut ( $\mathrm{mm}$, Cutting speed (rpm)

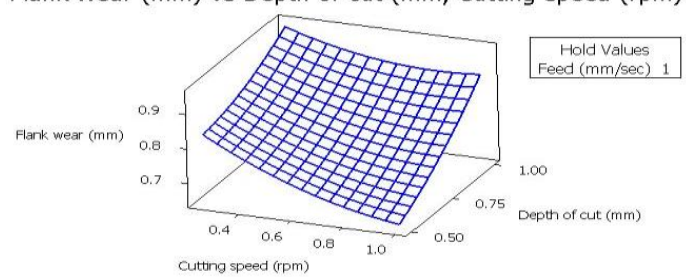

Fig.7. The various 3D plots for without MR fluid damper for different interaction ( $\mathrm{AB}, \mathrm{AC}$ and $\mathrm{BC}$ ) for flank wear. 


\section{Optimization of vibration parameters for boring bar operation by RSM and ANN}
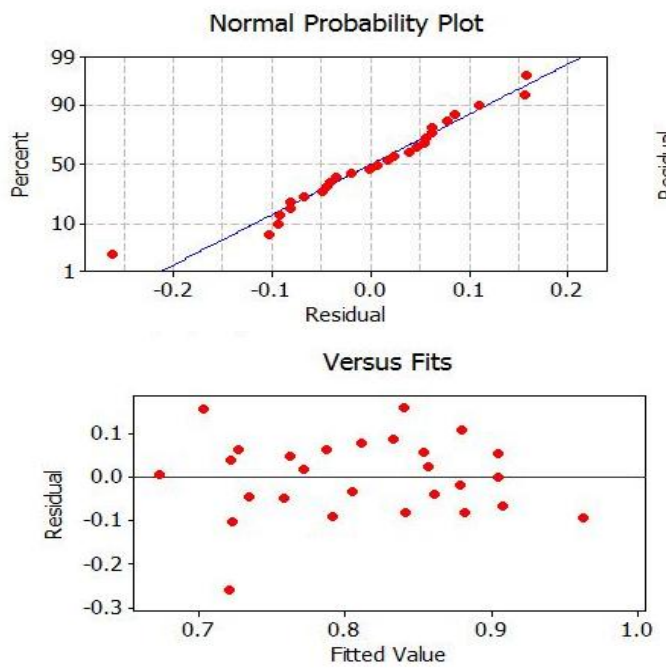

Fig.8. (a) Normal probability plot of residual for RMS data. (b) Plot of residual vs. fitted RMS (m/s2) values Residual Plots for Surfa
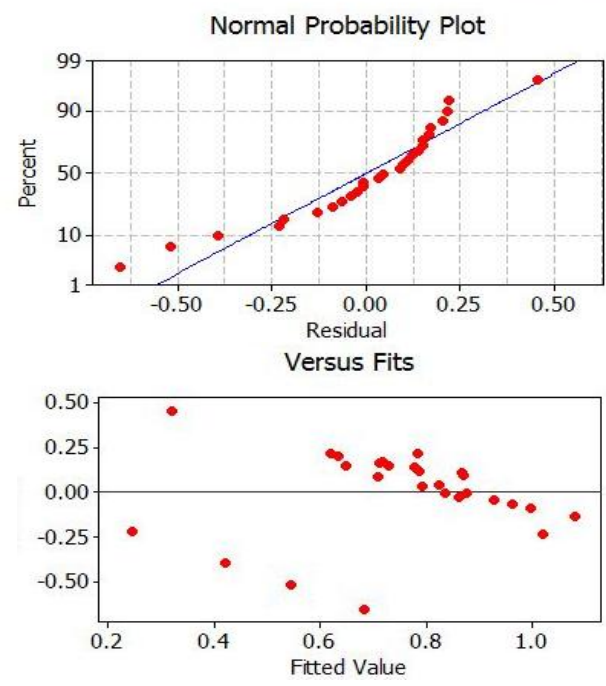

Fig.9. (a) Normal probability plot of residual for surface roughness data. (b) Plot of residual vs. fitted surface roughness values
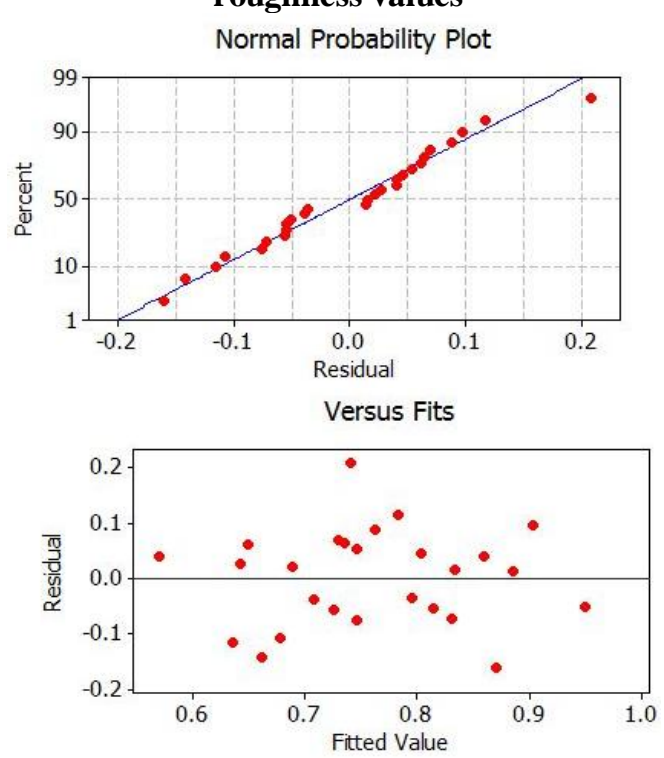

Fig.10.(a) Normal probability plot of residual for Flank wear data. (b) Plot of residual vs. fitted flank wear values
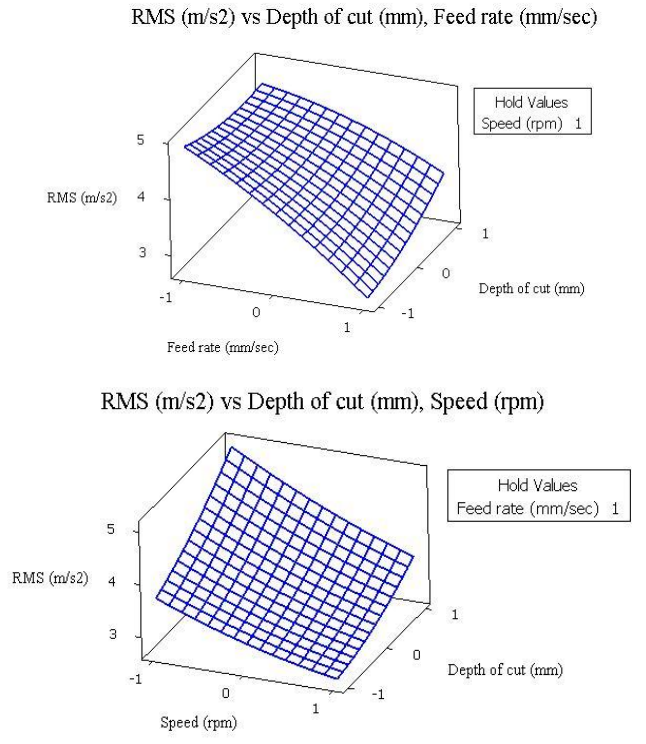

RMS $(\mathrm{m} / \mathrm{s} 2)$ vs Feed rate $(\mathrm{mm} / \mathrm{sec})$, Speed (rpm)

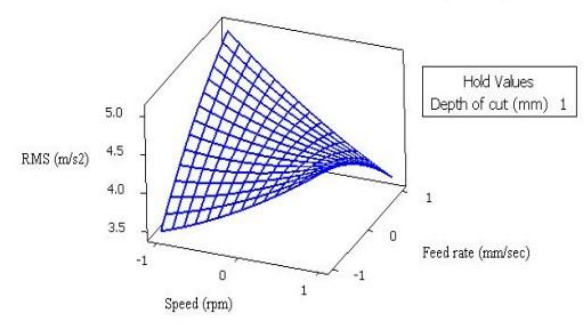

Fig.11. The various 3D plots for with MR fluid damper for different interaction (AB, AC and BC) for RMS acceleration signal.
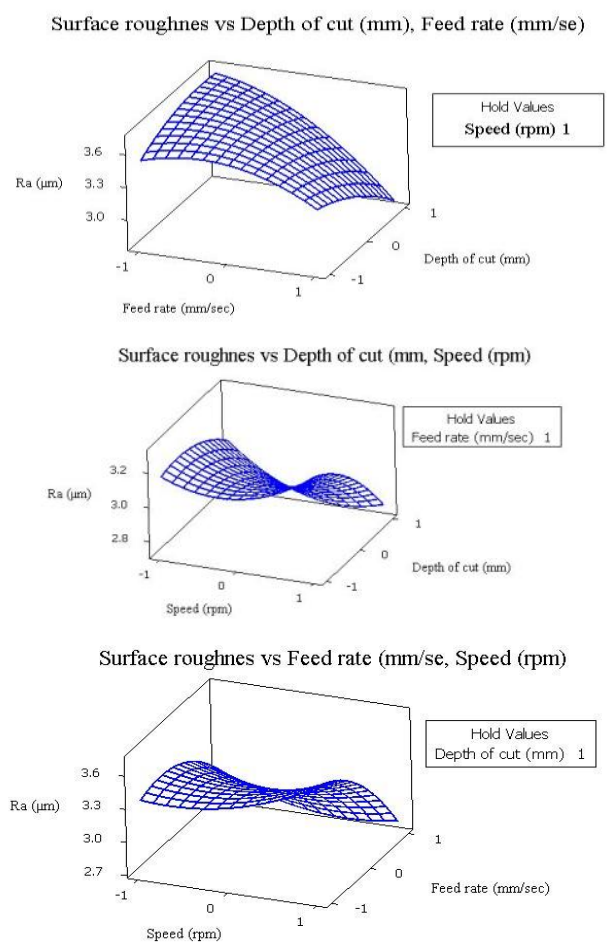

Fig.12. The various 3D plots for with MR fluid for different interaction (AB, AC and BC) for surface roughness

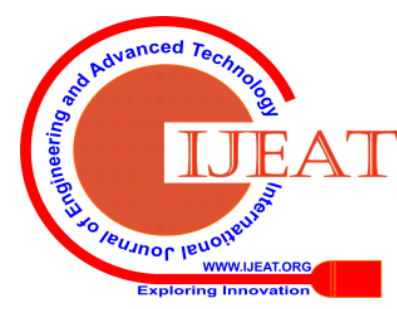


Flank wear $(\mathrm{mm})$ vs Feed rate $(\mathrm{mm} / \mathrm{sec})$, Speed $(\mathrm{rpm})$

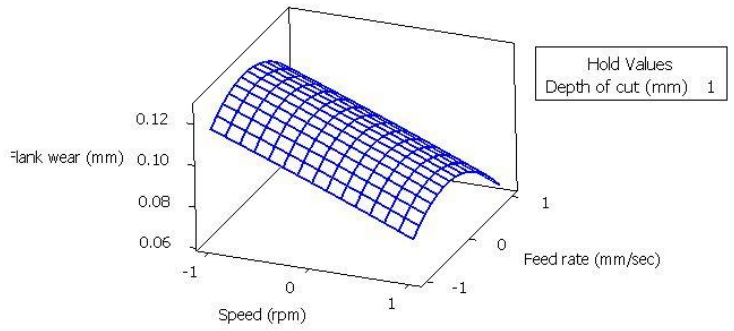

Flank wear (mm) vs Depth of cut (mm), Speed (rpm)

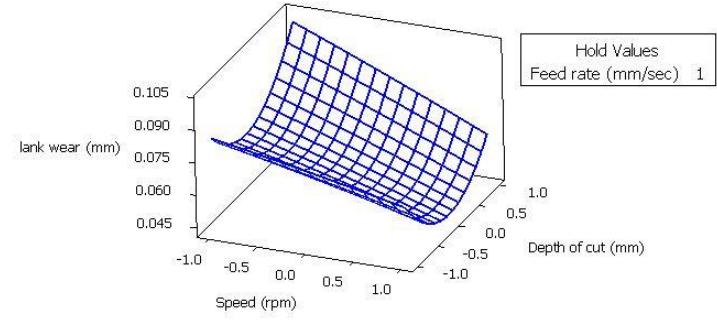

Flank wear (mm) vs Depth of cut ( $\mathrm{mm}$, Feed rate $(\mathrm{mm} / \mathrm{se}$

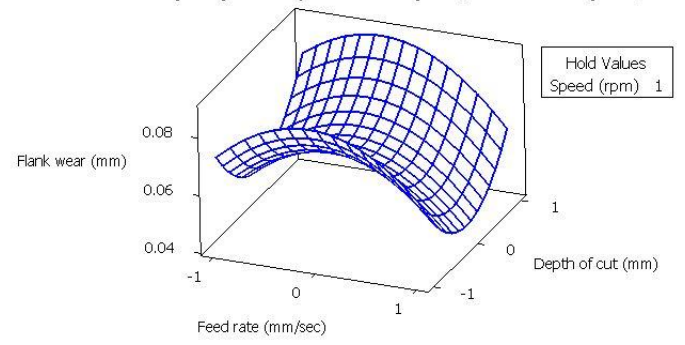

Fig.13.The various 3D plots for with MR fluid for different interaction (AB, AC and BC) for surface roughness

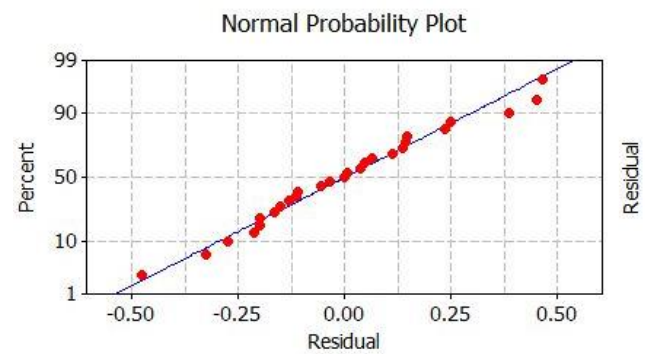

(a)

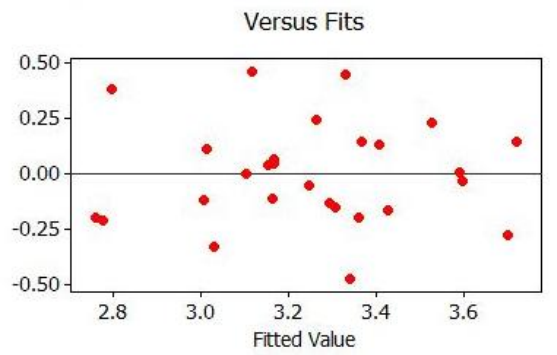

(b)

Fig.14. (a) Normal probability plot of residual for Flank wear data. (b) Plot of residual vs. fitted flank wear values

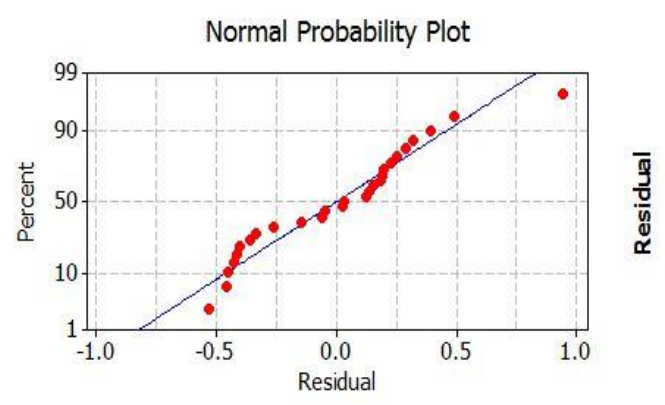

(a)

Versus Fits

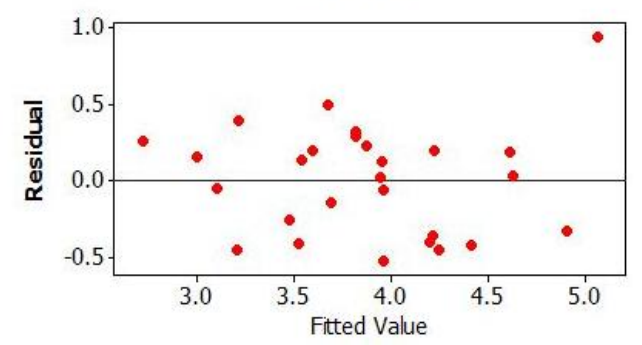

(b)

Fig.15. (a) Normal probability plot of residual for RMS data. (b) Plot of residual vs. fitted RMS (m/s2) values

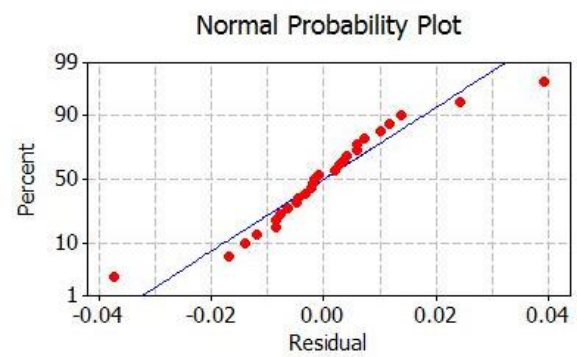

(a)

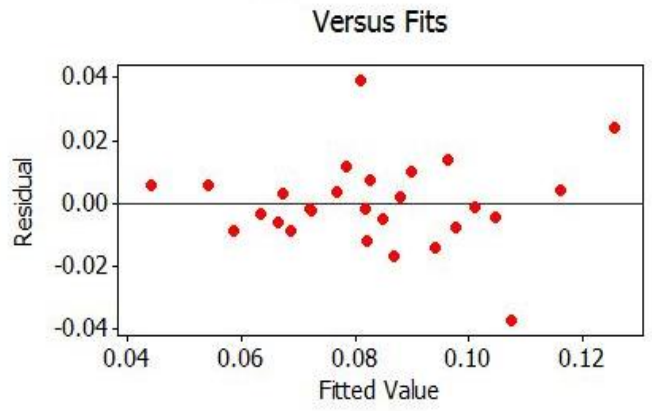

(b)

Fig.16. (a) Normal probability plot of residual for flank wear data. (b) Plot of residual vs. fitted flank wear values 


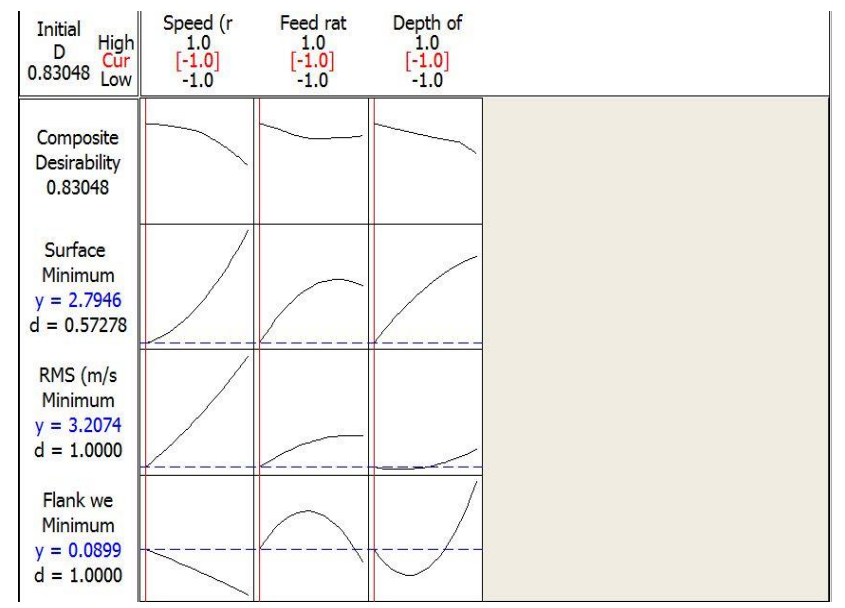

VII. CONCLUSION

In this paper, the application of RSM on machining the AISI 1018 steel is carried out for turning operation. A quadratic model have been developed for the surface roughness ( $\mathrm{Ra}$ ) to investigate the influence of the machining parameters. The results were as follows:

For the surface roughness, the feed rate is the main influencing factor in the roughness, followed by the tool nose radius and cutting speed. Depth of cut haveno significant effect in the surface roughness.

It can be seen that the interaction between of the most factors have no significant effect, except feed rate and tool nose radius which have the highest influence.

3D surface counter plots were useful in determining the optimum condition to obtain the particular values of the surface roughness.

Response surface optimization shows that the optimal combination of machining parameters were $(255.75 \mathrm{~m} / \mathrm{min}$, $0.1 \mathrm{~mm} / \mathrm{rev}, 0.3 \mathrm{~mm}, 1.2 \mathrm{~mm}$ ) for cutting speed, feed rate and depth of cut respectively.

Verification of experiments is carried out to show that the empirical models, which have beendeveloped, can be used for turning of AISI-410 steel within the $6 \%$ error.

\section{REFERENCES}

1. IhsanKorkut, YilmazKucuk, Experimental Analysis of the Deviation from Circularity of Bored Hole Based on the Taguchi Method, Strojniškivestnik - Journal of Mechanical Engineering 56 (2010) 5, 340-346.

2. A.K.M. Nurul Amin, SyidatulAkmaSulaiman, Siti Noor IzzatiMohdZainun and M. D. Arif, Surface Roughness Optimization in End Milling of Stainless Steel AISI 304 with Uncoated WC-Co Insert Under Magnetic Field, Advanced Materials Research Vol. 576 (2012) pp 119-122.

3. Harsimran Singh Sodhi, GauravVohra, Prediction of Optimized Parameters for CNC Boring Process using Taguchi Method for Steel, International Journal of Engineering Technology and Scientific Research Volume 1 Issue 1 (October 2013 Issue)

4. Giovanni Totis, Marco Sortino, Robust Analysis of Stability in Internal Turning, Procedia Engineering 69 ( 2014 ) 1306 - 1315.

5. L. Rubio, J.A. Loya, M.H. Miguelez, J. FernAndez-Saez Optimization of passive vibration absorbers to reduce chatter in boring, Mechanical Systems and Signal Processing, Volume 41, Issues 1-2, December 2013, Pages 691-704.

\section{AUTHORS PROFILE}

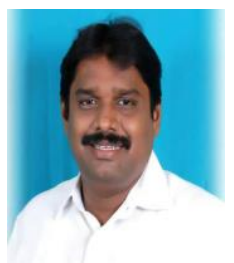

L.Prabhu - Associate Professor Department of Mechanical Engineering Aarupadai Veedu Institute of Technology Vinayaka Mission Research Foundation Deemed to be University

Prabhu@avit.ac.in 